\title{
Socio-economic disparities in the consumption of vegetables, fruit and energy-dense foods: the role of motive priorities
}

\author{
Hanna Konttinen ${ }^{1, *}$, Sirpa Sarlio-Lähteenkorva ${ }^{2}$, Karri Silventoinen ${ }^{1}$, Satu Männistö ${ }^{3}$ \\ and Ari Haukkala ${ }^{1}$ \\ 'Department of Social Research, University of Helsinki, PO Box 54, 00014 University of Helsinki, Helsinki, Finland: \\ ${ }^{2}$ Department of Public Health, University of Helsinki, Helsinki, Finland: ${ }^{3}$ Department of Chronic Disease Prevention, \\ National Institute for Health and Welfare, Helsinki, Finland
}

Submitted 16 June 2011: Final revision received 8 March 2012: Accepted 17 June 2012: First published online 3 August 2012

\begin{abstract}
Objective: A low socio-economic status (SES) is related to less healthy dietary habits, but the reasons for this remain unclear. We examined whether the absolute or relative importance of various food choice motives contributed to SES disparities in vegetable/fruit and energy-dense food intake.

Design: We analysed cross-sectional data from the FINRISK Study 2007 by means of structural equation modelling and used a shortened version of the Food Choice Questionnaire to assess the absolute importance of health, pleasure, convenience, price, familiarity and ethicality motives. We calculated the relative importance of each motive by dividing the participant's rating of it by his/her mean score on all motives. Dietary intake was measured with an FFQ.

Setting: A population-based survey in Finland.

Subjects: Men ( $n$ 1691) and women ( $n$ 2059) aged 25-64 years.

Results: Higher education and income were related to a greater vegetable/fruit intake $(\beta=0 \cdot 12, P<0 \cdot 001)$, while education was associated negatively with the consumption of energy-dense foods $(\beta=-0 \cdot 09, P<0 \cdot 001)$. Socio-economically disadvantaged individuals considered price and/or familiarity more important in their food choices in both absolute and relative terms. A higher income was related to a greater relative importance of health considerations. Relative motives were more strongly associated with vegetable/fruit and energy-dense food consumption than absolute motives and the relative importance of price, familiarity and health partly mediated the effects of the SES indicators on the consumption of these food items.

Conclusions: Individual priorities in food choice motives, rather than the absolute importance of single motives, play a role in producing SES disparities in diet.
\end{abstract}

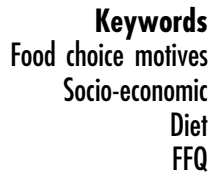

Numerous studies have shown that socio-economically disadvantaged individuals have less healthy dietary habits $^{(1,2)}$, which may contribute to a higher prevalence of obesity and consequently diet-related chronic diseases $^{(3)}$. Individuals with a lower socio-economic status (SES) tend to consume energy-dense foods more frequently, including energy-dense takeaway options, fatty meats and fried foods ${ }^{(2,4-7)}$, compared with their higher socio-economic counterparts who consume more fruit and vegetables ${ }^{(1,2)}$. However, the mechanisms explaining the SES inequalities in dietary intake are not fully understood. Food choice is a complex process and various individual, social and environmental factors are likely to contribute to socio-economic inequalities in food intakes. It has been proposed that motives underlying food selection play a role in explaining SES variations in diet, but few studies have tested this empirically ${ }^{(8-10)}$.
Previous research conducted in Europe and the USA has revealed that the most important food choice motives among adults are taste, health, price, and convenience of purchasing and preparation ${ }^{(11-13)}$. There is evidence that individuals with a low income or education place more importance on price and less importance on health in their food selection compared with their more educated or affluent counterparts ${ }^{(9,14,15)}$. Education may make individuals better able to process nutrition-related information and may socialize them to adopting healthy dietary habits. Furthermore, it has been shown that the cost of food is related to its nutritional quality, with lower priced products being nutritionally poor and energydense $^{(16)}$. Thus, by implication, it may be more difficult for individuals with fewer financial resources to take health aspects into account in their food purchasing decisions. Nevertheless, only one previous study has 
examined whether various health- and non-health-related motives contribute to SES disparities in food intake. That study found that a lower fibre intake among less educated individuals was partly attributable to the higher importance they placed on familiarity and sensory appeal of the food ${ }^{(8)}$.

A limitation of earlier studies is that they focus only on the absolute importance of food-related motives. Conflicts between personally relevant motives are common in specific food choice situations, making it necessary for individuals to prioritize them ${ }^{(17,18)}$. Price, taste and convenience can act as barriers to buying healthy food items, for example ${ }^{(19)}$. It would therefore be pertinent to explore the relative importance of each motive. Beydoun and Wang investigated the ratio of the importance of price relative to healthiness and found that low-SES individuals considered them both equally important, whereas those with a high SES put more emphasis on healthiness ${ }^{(20)}$. The ratio also partly explained the SES disparities in energy, fat, sodium and sugar intake. The conflict between price and health considerations is not the only one that can arise in relation to food choice, however, and thus it would be relevant to examine all motives relative to each other. The research emphasis in the related area of personal values has long been on individuals' value priorities (analysed by dividing respondents' scores on a single value by their mean ratings of all values) rather than on absolute ratings ${ }^{(21)}$. A similar approach could be adopted to investigate individual priorities in food choice motives, but we are not aware of any study that has done this.

The aim of the current study was to examine whether the absolute or relative importance of various food choice motives contributed to the education and income inequalities in dietary intake in a population-based sample of Finnish men and women. With respect to dietary intake, the focus was on the consumption of vegetables/fruit and energy-dense foods because (i) SES disparities are most consistently observed in the consumption of vegetables/ fruit $^{(1)}$ and (ii) energy-dense food items represent less healthy options that are typically affordable and purchased as pre-prepared food.

\section{Methods}

\section{Participants and setting}

The participants of the current study took part in two phases of the National Cardiovascular Risk Factor Survey (the FINRISK Study) conducted in $2007^{(22)}$. The ethical committee of the National Institute for Health and Welfare and the hospital districts gave their approval of the study protocols, and all participants gave their informed consent. For the FINRISK Study 2007, a random sample of 10000 people aged 25-74 years was drawn from the Finnish population register (representing all Finnish residents) in five geographic areas. The sample was stratified by gender, 10-year age groups and area. The first study phase took place from January to March 2007 and involved a total of 6258 individuals (a response rate of $63 \%$ ). The participants received by mail an invitation to undergo a health examination, together with a self-administered health questionnaire that yielded information on sociodemographic factors, health behaviour, and medical and disease history. They filled in the questionnaire at home and brought it with them when they came to the health centre for the examination.

All of the individuals who participated in the first study phase ( $n$ 6258) were invited to continue in the second phase conducted from April to June 2007, the aim of which was to investigate the dietary, lifestyle and genetic determinants of obesity and metabolic syndrome (the DILGOM sub-study). The response rate for this phase was $80 \%$ (2325 men and 2699 women). It comprised a further health examination at the health centre during which research nurses measured the weight and height of the participants and the participants completed a 132-item FFQ and questionnaires covering psychosocial (e.g. food choice motives) and lifestyle (e.g. physical activity) factors.

The sample for the present study consisted of all 25-64-year-old men ( $n$ 1691) and women ( $n$ 2059; i.e. working-age population) who participated in both study phases. Information on sociodemographic factors (years of education, gross household income, marital status and presence of children in the household) was derived from the first phase, whereas information related to other variables (food choice motives, dietary intake, weight, height and physical activity) was based on the second phase.

\section{Measures}

\section{Food choice motives}

Food choice motives were measured with a shortened version of the Food Choice Questionnaire (FCQ) ${ }^{(11)}$. The original FCQ includes thirty-six items and is intended to measure nine different motivational dimensions underlying the selection of food (health, mood, convenience, sensory appeal, natural content, price, weight control, familiarity and ethical concern). Respondents are asked to endorse the statement 'It is important to me that the food I eat on a typical day...' for each item, on a four-point scale (ranging from $1=$ not at all important to $4=$ very important). However, the factor structure of the FCQ has not been well replicated in other studies $^{(23,24)}$, and Fotopoulos et al. suggest reducing the number of motivational dimensions and using fewer items to measure each one ${ }^{(24)}$. We excluded thirteen items that had content overlap with other items, and added three items measuring ethical/political aspects of food purchasing (items 20, 22 and 26 in Appendix), which are currently relevant in the Finnish context. Confirmatory factor analysis implied that the original nine-factor structure had a poor 
fit with the data $\left(\chi^{2}=3781 \cdot 08, \quad\right.$ df $=265, \quad P<0 \cdot 001$; CFI (comparative fit index) $=0 \cdot 89$; TLI (Tucker-Lewis index) $=0 \cdot 87$; RMSEA (root mean square error of approximation $)=0.06 ;$ SRMR (standardized root mean square residual $=0 \cdot 06$ ) according to cut-off points suggested by $\mathrm{Hu}$ and Bentler ${ }^{(25)}$. A series of exploratory factor analyses (maximum likelihood extraction with oblimin with Kaiser normalization oblique rotation) clearly supported the four-factor structure (the scree plot $^{(26)}$ indicated that adding a fifth or more factors would not significantly increase the total variance explained in the items). These four factors were interpreted as health, pleasure, convenience and ethicality (Appendix). Three items did not clearly load on any of the factors (all loadings <0.35). We excluded one of them ('is high in protein') from the present analyses and analysed the other two as separate variables because they were the only items measuring the familiarity ('is what I usually eat') and price ('is cheap') dimensions of the original FCQ. All in all, we measured the health dimension on eight items, convenience on three items, pleasure on five items, ethicality on seven items and both familiarity and price on one item.

We derived the absolute importance of health, pleasure, convenience and ethicality by calculating the mean score of the items belonging to the respective factors, whereas the participant's rating of price and familiarity reflected the absolute importance of these two motives. We computed the relative importance of each motive by dividing the participant's absolute rating of it by his/her mean score on all twenty-five motive items. The same method has been used to calculate individuals' value priorities in studies on personal values ${ }^{(27,28)}$

Consumption of vegetables/fruit and energy-dense foods Vegetable/fruit and energy-dense food consumption was assessed with the validated FFQ, which inquires into the average use frequencies of 132 food items common in the current Finnish diet during the previous 12 months ${ }^{(29,30)}$. There are nine possible frequency categories for all of the items, ranging from never or seldom to more than six times a day. The portion size was fixed for each one and if possible specified in natural units (e.g. glass, slice). The average intakes of fresh vegetables/fruit (sixteen items, potatoes were not included) and energy-dense foods (eight items including savoury pasties, pizza, hamburgers, fried potatoes, sausages and mayonnaise salads) were the food consumption variables of interest in the present analyses. We used the Finnish national food composition database (Fineli) of the National Institute for Health and Welfare to calculate the average daily consumption of vegetables $(\mathrm{g})$, fruit $(\mathrm{g})$ and energy-dense foods $(\mathrm{g})$ and total energy intake $(\mathrm{kJ})$ from the $\mathrm{FFQ}^{(31)}$.

\section{Sociodemographic factors}

Self-reported total years of schooling were used to measure education on a continuous scale. Participants were asked to report their previous year's gross household income on a nine-point scale ranging from less than $€ 10000$ to more than $€ 80000$. Household income was subsequently divided by the weighted sum of the number of household adult and child members (a weight of $1 \cdot 0$ was given for the first adult of the household, 0.7 for all other adults and 0.5 for children under the age of 17 years), as recommended by the Organisation for Economic Co-operation and Development ${ }^{(32)}$.

Age, marital status, having children in the household, BMI and physical activity were included as covariates in the analyses. Age was used as a continuous variable and marital status was dichotomized into married/cohabiting $v$. single. Households were categorized into those with children under the age of 17 years and those without children. BMI was calculated as weight in kilograms (measured to the nearest $100 \mathrm{~g}$ in light clothing without shoes) divided by the square of height in metres (measured to the nearest $0.5 \mathrm{~cm}$ ). Two questions derived from the validated short form of the International Physical Activity Questionnaire (IPAQ) ${ }^{(33)}$ were used to assess the number of days during the previous week on which the participants engaged in vigorous (e.g. running or lifting heavy weights) or moderate (e.g. light jogging) physical activity for at least $10 \mathrm{~min}$.

\section{Statistical metbods}

We analysed the bivariate associations between the study variables by means of age-adjusted partial Pearson's correlations using the SPSS statistical software package version $15 \cdot 0$. The next stage was to test the hypothesized mediation model between SES, food choice motives and dietary intake (Fig. 1) by means of structural equation modelling and using Mplus statistical software version $6 \cdot 0^{(34)}$. We estimated the mediation model separately for all SES indicators (education and income), the food choice motives (absolute and relative) and the food consumption variables (intake of vegetables/fruit and energy-dense foods). The models were adjusted for gender, age, marital status, having children in the household, BMI, physical activity and total energy intake. However in order to avoid over-adjustment, we did not adjust the analyses of energy-dense foods for energy intake because such foods have high energy content by definition. We used Mplus ${ }^{(34)}$ to derive the total, direct and indirect (through each absolute and relative food choice motive) effects of the SES indicators on the food consumption variables and their respective standard errors (see Fig. 1). Maximum likelihood robust (MLR) was used as an estimation method given that the distributions of the study variables deviated from normality to some extent. MLR produces standard errors (by means of a sandwich estimator) and a $\chi^{2}$ test statistic that are robust for non-normality ${ }^{(34)}$. We did not evaluate the model fit because the estimated mediation models had zero degrees of freedom and thus, by definition, fitted the data perfectly. 


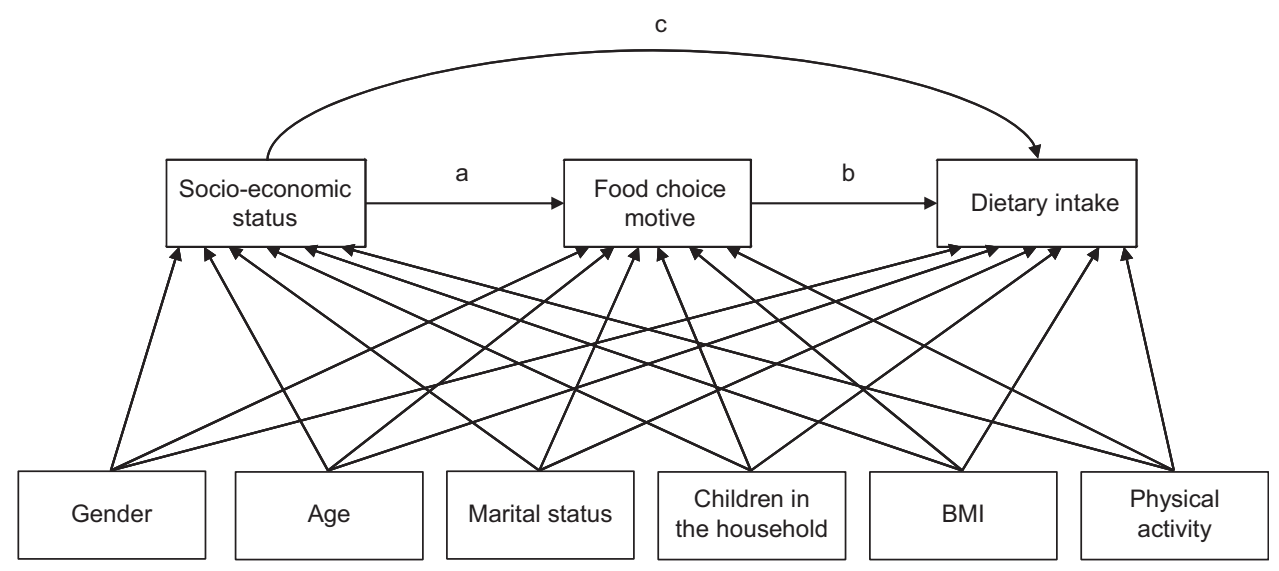

Fig. 1 The mediation model used to estimate the effects of socio-economic indicators on dietary intake. The model was estimated separately for each socio-economic indicator (education and income), absolute and relative food choice motive and food consumption variable (vegetables/fruit and energy-dense foods). All models were adjusted for age, gender, marital status, children in the household, BMI and physical activity. The models for vegetables/fruit were also adjusted for total energy intake. Rectangles represent the measured variables and arrows the regression paths between the variables. $a=$ Direct effect of socio-economic indicator on food choice motive; $b=$ direct effect of food choice motive on dietary intake; $c=$ direct effect of socio-economic indicator on dietary intake; $a \times b=$ indirect effect of the socio-economic indicator on dietary intake through the food choice motive. Total effect of the socio-economic indicator on dietary intake $=$ direct effect $c+$ indirect effect $a \times b$

The correlations and descriptive characteristics of the study sample are shown by gender because men and women differ considerably with respect to dietary intake and motives for food choices ${ }^{(11,35)}$. However, we carried out multi-group analyses in order to formally test gender differences related to the mediation models: the $\chi^{2}$ statistic of the constrained models (the regression paths $\mathrm{a}, \mathrm{b}$ and $\mathrm{c}$ shown in Fig. 1 were forced to be similar between genders) was compared with that of the unconstrained models (the three paths were allowed to vary freely) using $\chi^{2}$ difference tests (taking into account the MLR scaling-correction factor). If the $\chi^{2}$ statistic of the constrained model was significantly different from that of the unconstrained model, the gender-stratified total, direct and indirect effects are shown. We used an $\alpha$ level of $P<0.01$ instead of $P<0 \cdot 05$, given the sensitivity of the $\chi^{2}$ difference test to sample size that makes small differences statistically significant in large samples ${ }^{(36)}$.

\section{Results}

Table 1 presents the descriptive characteristics of the study sample. Both men and women rated health and pleasure as the two most important food choice motives, followed by convenience and price, irrespective of whether absolute or relative motives were analysed. Women placed more importance on health, pleasure, ethicality, convenience and price in their daily food choice than men, whereas men scored more highly on familiarity (Table 1). In contrast, health and familiarity were the only relative motives showing significant gender differences.

All six absolute food choice motives correlated positively with each other, the strongest correlation being between health and ethicality $(r=0.55$ in men and $r=0.48$ in women; Table 2). When the relative importance of the motives was analysed, the associations changed substantially in both genders: health, pleasure and ethicality correlated negatively with almost all of the other motives, whereas convenience, familiarity and price were positively related. However, each relative motive had a positive and high correlation with its absolute counterpart, ranging from 0.67 to 0.87 among men and from 0.60 to 0.92 among women.

As the age-adjusted correlation coefficients in Table 3 show, participants with a higher education and income rated price and familiarity as less important in both absolute and relative terms. A minor gender difference was observed here: the relationship between education and price was significant only among women. A higher income was related to the greater relative importance of health considerations in food selection. On the relative level, all of the motives were significantly associated with the food consumption variables: pleasure, convenience, price and familiarity were associated with a lower consumption of vegetables/fruit and a higher consumption of energy-dense foods, whereas the opposite was the case with health and ethicality (Table 3). On the absolute level, all of the motives except health and ethicality correlated weakly with vegetable/fruit and energy-dense food intake $(r \leq|0 \cdot 10|)$.

Tables 4 and 5 show the standardized total, direct and indirect effects of respectively education and income on vegetable/fruit and energy-dense food intake from the mediation models. Education (total effect $\beta=0 \cdot 12$, $P<0 \cdot 001$ ) and income (total effect $\beta=0 \cdot 12, P<0 \cdot 001$ ) were related to a higher consumption of vegetables/fruit, whereas education had an inverse association with energy-dense food intake (total effect $\beta=-0 \cdot 09$, 
Table 1 Characteristics of the study participants by gender: sub-sample of men and women aged 25-64 years, FINRISK Study 2007

\begin{tabular}{|c|c|c|c|c|}
\hline & \multicolumn{2}{|c|}{ Men ( $n$ 1616-1691) } & \multicolumn{2}{|c|}{ Women (n 1946-2059) } \\
\hline & Mean or $\%$ & SD & Mean or $\%$ & SD \\
\hline Age (years) & $47 \cdot 6^{\star}$ & $10 \cdot 8$ & $46 \cdot 6$ & $11 \cdot 1$ \\
\hline Education (years) & $13 \cdot 0^{*}$ & $3 \cdot 7$ & $13 \cdot 8$ & $3 \cdot 7$ \\
\hline Household income $(€)$ & $26133 \cdot 4^{*}$ & $14468 \cdot 7$ & $25057 \cdot 9$ & $13391 \cdot 3$ \\
\hline Married (\%) & $74 \cdot 7$ & - & $72 \cdot 3$ & - \\
\hline Children in the household (\%) & $32 \cdot 7$ & - & $35 \cdot 4$ & - \\
\hline Physical activity (times/week) & $4 \cdot 3^{*}$ & $3 \cdot 6$ & $3 \cdot 7$ & $3 \cdot 1$ \\
\hline BMl $\left(\mathrm{kg} / \mathrm{m}^{2}\right)$ & $27 \cdot 0^{*}$ & $4 \cdot 3$ & $26 \cdot 4$ & $5 \cdot 4$ \\
\hline Vegetables/fruit (g/d) & $338 \cdot 6^{*}$ & $258 \cdot 1$ & $485 \cdot 5$ & $321 \cdot 5$ \\
\hline Energy-dense foods $(\mathrm{g} / \mathrm{d})$ & $122 \cdot 4^{\star}$ & $87 \cdot 6$ & $66 \cdot 7$ & $51 \cdot 5$ \\
\hline Total energy intake $(\mathrm{kJ} / \mathrm{d})$ & $11566 \cdot 8^{*}$ & $3854 \cdot 9$ & $9338 \cdot 1$ & $3087 \cdot 7$ \\
\hline \multicolumn{5}{|l|}{ Absolute food choice motivest } \\
\hline Health & $2 \cdot 82^{*}$ & 0.51 & $3 \cdot 10$ & $0 \cdot 48$ \\
\hline Pleasure & $2 \cdot 83^{\star}$ & 0.51 & 3.03 & 0.52 \\
\hline Ethicality & $2 \cdot 36^{\star}$ & 0.55 & $2 \cdot 52$ & 0.57 \\
\hline Convenience & $2 \cdot 62^{\star}$ & 0.59 & $2 \cdot 81$ & 0.59 \\
\hline Familiarity & $2 \cdot 34^{\star}$ & $0 \cdot 68$ & $2 \cdot 26$ & 0.75 \\
\hline Price & $2 \cdot 63^{\star}$ & $0 \cdot 71$ & $2 \cdot 79$ & $0 \cdot 70$ \\
\hline \multicolumn{5}{|l|}{ Relative food choice motivesł } \\
\hline Health & $1 \cdot 06^{*}$ & $0 \cdot 12$ & $1 \cdot 09$ & $0 \cdot 11$ \\
\hline Pleasure & $1 \cdot 08$ & $0 \cdot 17$ & $1 \cdot 07$ & $0 \cdot 16$ \\
\hline Ethicality & $0 \cdot 89$ & $0 \cdot 14$ & $0 \cdot 88$ & $0 \cdot 14$ \\
\hline Convenience & $1 \cdot 00$ & 0.24 & $1 \cdot 00$ & 0.22 \\
\hline Familiarity & $0.89^{\star}$ & 0.26 & 0.80 & 0.25 \\
\hline Price & 1.00 & $0 \cdot 27$ & 0.99 & 0.25 \\
\hline
\end{tabular}

Mean values were significantly different from those of women (ANOVA): ${ }^{\star} P<0.05$.

+Values vary from 1 to 4 .

$\ddagger$ Values vary from $0 \cdot 27$ to $2 \cdot 86$.

$P<0 \cdot 001$ ). The absolute importance of price, familiarity and ethicality significantly mediated the effects of the SES indicators on the intake of vegetables/fruit and/or energy-dense foods, but all of these indirect effects were very small in magnitude $(\beta \leq|0 \cdot 010|)$. The sizes of the indirect effects were larger in the models including relative motives, and health, price and familiarity partly attenuated the associations between the SES indicators and the food consumption variables. Multi-group analyses indicated significant $(P \leq 0 \cdot 01)$ gender differences in the associations between education, price and food consumption variables: the indirect effects of education through price (absolute and relative importance) on vegetable/fruit and energy-dense food intake were significant only among women (Table 4).

\section{Discussion}

The purpose of the current study was to increase understanding of the underlying reasons for SES inequalities in dietary intake. We concentrated on the role of food choice motives and, more specifically, considered whether individuals' motive priorities (i.e. relative motives) should be analysed rather than their absolute ratings of single motives (i.e. absolute motives). We identified six distinctive food choice motives, including health, pleasure, convenience, price, familiarity and ethicality. Participants with low levels of education and income placed more importance on price and familiarity of the food than their more educated and affluent counterparts in both absolute and relative terms. A minor gender difference was that education was associated with price motive (absolute and relative) only among women. Furthermore, a higher income was related to the greater relative importance of health considerations in both genders. The relative rather than the absolute importance of price, health and familiarity partly explained the SES gradient in the intake of vegetables/fruit and/or energydense foods.

The well-established positive relationship between SES and vegetable/fruit consumption ${ }^{(1,2)}$ was replicated in the present study with respect to both educational attainment and household income. In contrast, only education showed a negative association with energy-dense food intake, which is consistent with results from a recent study on SES differences in takeaway food consumption ${ }^{(5)}$. The finding that the importance of price, familiarity and health motives varied among the SES groups supports the results of previous studies on this issue ${ }^{(8-10,14,15)}$, although for the health motive we observed this only on the relative level. As expected, the relationship between income and price was the strongest of all the associations between the motives and the SES indicators. It is reasonable for individuals with fewer financial resources to emphasize price in their food purchasing decisions and there is evidence that price is a barrier to purchasing healthy food items 
among socio-economically disadvantaged groups ${ }^{(37-40)}$. The greater importance attached to familiarity among individuals with lower levels of education and income could result in a more monotonous dietary intake. Trying new food may, for example, represent a risk of waste that less affluent individuals cannot afford to take ${ }^{(41)}$. Moreover, a higher education may increase the willingness to experiment with new foods, thereby leading to a lower appreciation of food-related traditions and familiar dietary practices ${ }^{(39)}$. The finding that considerations related to weight control and health were relatively more salient to individuals with higher incomes could, to some extent, reflect the fact that more affluent individuals have the financial freedom to take health aspects into account in their food purchasing, given the higher cost of healthy foods ${ }^{(16)}$.

The present study is the first one to show that the relative importance of price, health and familiarity motives contributes to SES disparities in the consumption of vegetables/fruit and/or energy-dense foods. The mediated effects of the absolute motives were very small, however, although there were some significant indirect effects. The difference between the absolute and relative price and familiarity motives can be attributed to the fact that they were associated with a lower vegetable/fruit intake and a higher energy-dense food intake on the relative level, whereas on the absolute level their associations with these food consumption variables were weak. Similarly, a previous study (analysing motives in absolute terms) found that education groups differed in the importance they placed on four motives (price, familiarity, mood control and sensory appeal), but only familiarity contributed to the educational gradient in total fibre and fruit/vegetable intake ${ }^{(8)}$. The findings from the present study extend those obtained by Beydoun and Wang concerning the importance of price relative to healthiness as a contributor to SES disparities in diet ${ }^{(20)}$ in indicating a need to analyse other food choice motives relative to each other. It should be noted, however, that the relative motives explained only part of the SES variations in dietary intake, implying that other factors are also relevant. Factors related to the food environment, such as access and availability, have recently attracted a lot of research interest and poorer access to healthy foods has been observed in socio-economically deprived areas in the $\mathrm{USA}^{(42)}$. For other high-income countries including the UK, Canada and Australia, the evidence for poorer access to healthy foods in disadvantaged areas is equivocal $^{(42,43)}$.

Another discrepancy between absolute and relative motives was that all of the absolute motives correlated positively with each other, in accordance with findings reported in previous studies ${ }^{(11,44)}$, but convenience, familiarity and price were the only relative ones that were positively associated. The occurrence of negative as well as positive correlations on the relative level is 
Table 3 Age-adjusted correlations between absolute and relative food choice motives, socio-economic indicators and food consumption variables by gender: sub-sample of men and women aged 25-64 years, FINRISK Study 2007

\begin{tabular}{|c|c|c|c|c|c|c|c|c|}
\hline & \multicolumn{4}{|c|}{ Men ( $n$ 1616-1686) } & \multicolumn{4}{|c|}{ Women (n 1946-2047) } \\
\hline & Education & Income & $\begin{array}{c}\text { Vegetables/ } \\
\text { fruitt }\end{array}$ & $\begin{array}{l}\text { Energy-dense } \\
\text { foodst }\end{array}$ & Education & Income & $\begin{array}{l}\text { Vegetables/ } \\
\text { fruitt }\end{array}$ & $\begin{array}{l}\text { Energy-dense } \\
\text { foodst }\end{array}$ \\
\hline \multicolumn{9}{|l|}{ Absolute motives } \\
\hline Health & 0.04 & 0.03 & $0 \cdot 25^{\star \star \star}$ & $-0 \cdot 19^{\star \star \star}$ & -0.01 & 0.02 & $0 \cdot 23^{\star \star \star}$ & $-0 \cdot 23^{\star \star \star}$ \\
\hline Pleasure & -0.02 & -0.02 & $0.05^{\star}$ & $0.06^{\star}$ & $-0.08^{\star \star \star}$ & -0.02 & 0.04 & 0.00 \\
\hline Ethicality & -0.01 & $-0.06^{\star}$ & $0 \cdot 15^{\star \star \star}$ & $-0 \cdot 14^{\star \star \star}$ & 0.01 & $-0 \cdot 05^{\star}$ & $0 \cdot 14^{\star \star \star}$ & $-0 \cdot 11^{\star \star \star}$ \\
\hline Convenience & 0.01 & $-0.08^{\star \star}$ & $-0.06^{\star}$ & $0 \cdot 10^{\star \star \star}$ & 0.04 & 0.00 & $-0 \cdot 06^{\star}$ & $0 \cdot 08^{\star \star \star}$ \\
\hline Price & 0.01 & $-0 \cdot 26^{\star \star \star}$ & $-0 \cdot 06^{\star}$ & 0.02 & $-0 \cdot 15^{\star \star \star}$ & $-0 \cdot 32^{\star \star \star}$ & $-0 \cdot 08^{\star \star}$ & $0.06^{*}$ \\
\hline Familiarity & $-0 \cdot 13^{\star \star \star}$ & $-0 \cdot 11^{\star \star \star}$ & $-0.08^{\star *}$ & 0.03 & $-0 \cdot 19^{\star \star *}$ & $-0 \cdot 11^{\star * \star}$ & -0.01 & $0.07^{\star \star}$ \\
\hline \multicolumn{9}{|l|}{ Relative motives } \\
\hline Health & $0.07^{\star *}$ & $0 \cdot 14^{\star \star \star}$ & $0 \cdot 20^{\star \star \star}$ & $-0 \cdot 19^{\star \star \star}$ & 0.04 & $0 \cdot 10^{\star \star \star}$ & $0 \cdot 19^{\star \star \star}$ & $-0 \cdot 22^{\star \star \star}$ \\
\hline Pleasure & -0.04 & 0.02 & $-0.09^{\star \star \star}$ & $0 \cdot 17^{\star \star \star}$ & $-0.06^{\star \star}$ & 0.03 & $-0.09^{\star \star \star}$ & $0 \cdot 12^{\star \star \star}$ \\
\hline Ethicality & -0.00 & -0.04 & $0 \cdot 09^{\star \star \star}$ & $-0 \cdot 12^{\star \star \star}$ & $0 \cdot 06^{\star \star}$ & -0.03 & $0 \cdot 09^{\star \star \star}$ & $-0 \cdot 07^{\star \star}$ \\
\hline Convenience & 0.00 & 0.04 & $-0 \cdot 16^{\star \star \star}$ & $0 \cdot 15^{\star \star \star}$ & $0.06^{\star}$ & 0.03 & $-0 \cdot 17^{\star \star \star}$ & $0 \cdot 16^{\star \star *}$ \\
\hline Price & -0.01 & $-0 \cdot 24^{\star \star \star}$ & $-0 \cdot 15^{\star \star \star}$ & $0 \cdot 08^{* *}$ & $-0 \cdot 13^{\star \star *}$ & $-0 \cdot 30^{\star \star \star}$ & $-0 \cdot 17^{\star \star \star}$ & $0 \cdot 12^{\star \star \star}$ \\
\hline Familiarity & $-0 \cdot 13^{\star \star \star}$ & $-0 \cdot 08^{\star \star}$ & $-0 \cdot 17^{\star \star \star}$ & $0.09^{\star \star}$ & $-0 \cdot 19^{\star \star \star}$ & $-0.09^{\star \star \star}$ & $-0.09^{\star \star \star}$ & $0 \cdot 13^{\star \star \star}$ \\
\hline
\end{tabular}

Significance of correlation: ${ }^{\star} P<0.05,{ }^{\star \star} P<0.01,{ }^{\star \star \star} P<0.001$.

tThe food consumption variables were square-root transformed in order to improve the normality of the distributions.

Table 4 Results from the structural equation models: standardized total, direct and indirect (through food choice motives) effects of education on the consumption of vegetables/fruit and energy-dense foods among a sub-sample of men and women aged 25-64 years, FINRISK Study 2007

\begin{tabular}{|c|c|c|c|c|c|c|c|c|c|c|}
\hline & \multirow{2}{*}{\multicolumn{2}{|c|}{$\begin{array}{l}\text { Total effect of } \\
\text { educationt }\end{array}$}} & \multicolumn{4}{|c|}{ Models with absolute food choice motives } & \multicolumn{4}{|c|}{ Models with relative food choice motives } \\
\hline & & & \multicolumn{2}{|c|}{$\begin{array}{l}\text { Direct effect of } \\
\text { education }\end{array}$} & \multicolumn{2}{|c|}{$\begin{array}{l}\text { Specific indirect } \\
\text { effects }\end{array}$} & \multicolumn{2}{|c|}{$\begin{array}{l}\text { Direct effect of } \\
\text { education }\end{array}$} & \multicolumn{2}{|c|}{$\begin{array}{l}\text { Specific indirect } \\
\text { effects }\end{array}$} \\
\hline & $\beta$ & SE & $\beta$ & SE & $\beta$ & SE & $\beta$ & SE & $\beta$ & SE \\
\hline \multicolumn{11}{|c|}{ Vegetables/fruit§ ( $n$ 3565) } \\
\hline Health & $0 \cdot 12^{\star \star *}$ & 0.02 & $0 \cdot 11^{\star \star *}$ & 0.02 & 0.005 & 0.004 & $0 \cdot 11^{\star \star *}$ & 0.02 & $0 \cdot 010^{\star *}$ & 0.004 \\
\hline Pleasure & $0 \cdot 12^{\star \star \star}$ & 0.02 & $0 \cdot 12^{\star \star \star}$ & 0.02 & -0.001 & 0.001 & $0 \cdot 11^{\star \star \star}$ & 0.02 & $0.004^{*}$ & 0.002 \\
\hline Ethicality & $0 \cdot 12^{\star \star \star}$ & 0.02 & $0 \cdot 11^{\star \star \star}$ & 0.02 & 0.001 & 0.002 & $0 \cdot 11^{\star \star \star}$ & 0.02 & 0.002 & 0.001 \\
\hline Convenience & $0 \cdot 12^{\star \star \star}$ & 0.02 & $0 \cdot 12^{\star \star \star}$ & 0.02 & -0.002 & 0.001 & $0 \cdot 12^{\star \star \star}$ & 0.02 & $-0.006^{\star}$ & 0.003 \\
\hline \multicolumn{11}{|l|}{ Priceł } \\
\hline Men & $0 \cdot 15^{\star \star \star}$ & 0.03 & $0 \cdot 15^{\star \star \star}$ & 0.03 & 0.000 & 0.002 & $0 \cdot 14^{\star \star \star}$ & 0.03 & 0.003 & 0.004 \\
\hline Women & $0.09^{\star \star \star}$ & 0.02 & $0.08^{\star \star \star}$ & 0.02 & $0.009^{*}$ & 0.003 & $0.07^{\star \star}$ & 0.02 & $0.019^{\star \star *}$ & 0.004 \\
\hline Familiarity & $0 \cdot 12^{\star \star \star}$ & 0.02 & $0 \cdot 11^{\star \star \star}$ & 0.02 & $0.005^{\star}$ & 0.003 & $0 \cdot 10^{\star \star \star}$ & 0.02 & $0 \cdot 017^{\star \star \star}$ & 0.003 \\
\hline \multicolumn{11}{|c|}{ Energy-dense foods $\$(n 3620)$} \\
\hline Health & $-0.09^{* \star *}$ & 0.02 & $-0.09^{\star \star \star}$ & 0.02 & -0.004 & 0.004 & $-0.08^{\star * *}$ & 0.02 & $-0 \cdot 010^{\star *}$ & 0.004 \\
\hline Pleasure & $-0.09^{\star \star *}$ & 0.02 & $-0.09^{\star \star \star}$ & 0.02 & -0.001 & 0.001 & $-0.08^{\star * *}$ & 0.02 & $-0.006^{\star}$ & 0.003 \\
\hline Ethicality & $-0.09^{\star \star \star}$ & 0.02 & $-0.09^{\star \star \star}$ & 0.02 & 0.000 & 0.002 & $-0.09^{\star \star \star}$ & 0.02 & -0.002 & 0.002 \\
\hline Convenience & $-0.09^{\star \star \star}$ & 0.02 & $-0.09^{\star \star \star}$ & 0.02 & 0.003 & 0.002 & $-0 \cdot 10^{\star * \star}$ & 0.02 & $0.006^{\star}$ & 0.003 \\
\hline \multicolumn{11}{|l|}{ Price } \\
\hline Men & $-0.06^{*}$ & 0.03 & $-0.06^{\star}$ & 0.03 & 0.000 & 0.001 & $-0.06^{\star}$ & 0.03 & -0.002 & 0.002 \\
\hline Women & $-0 \cdot 14^{\star \star \star}$ & 0.03 & $-0 \cdot 13^{\star \star \star}$ & 0.03 & -0.004 & 0.004 & $-0 \cdot 12^{\star \star \star}$ & 0.03 & $-0.013^{\star \star}$ & 0.004 \\
\hline Familiarity & $-0.09^{* \star \star}$ & 0.02 & $-0.09^{\star \star \star}$ & 0.02 & -0.005 & 0.003 & $-0.08^{* * *}$ & 0.02 & $-0.014^{\star \star *}$ & 0.003 \\
\hline
\end{tabular}

Significance of coefficient: ${ }^{\star} P<0.05,{ }^{\star *} P<0.01,{ }^{\star \star *} P<0.001$.

$\uparrow$ Total effect $=$ direct effect + indirect effect.

$\ddagger$ Gender-stratified results are shown because the multi-group analyses indicated significant $(P \leq 0 \cdot 01)$ gender differences in the associations between education, price and the food consumption variables.

$\S$ The food consumption variables were square-root transformed in order to improve the normality of the distributions.

understandable in that each motive was divided by the individual mean ratings across all motives in order to determine its relative importance. People commonly prioritize food choice motives, given that it is rare for all personally important motives to be fully satisfied in any particular eating situation ${ }^{(17,18)}$, and relative motive variables produce the prioritizing mathematically. One problem related to relative motives is that they do not capture individual differences in the level of involvement with food, some consumers being enthusiastic about every aspect of it and others being extremely uninvolved ${ }^{(45)}$. However, analysing motive priorities instead of absolute ratings of single motives may better reflect the complexity of the motive structure in that relatively unimportant motives might not affect food choices even though their absolute importance is high ${ }^{(46)}$.

One of the strengths of the current study was that we used a large population-based sample incorporating 
Table 5 Results from the structural equation models: standardized total, direct and indirect (through food choice motives) effects of income on the consumption of vegetables/fruit and energy-dense foods among a sub-sample of men and women aged 25-64 years, FINRISK Study 2007

\begin{tabular}{|c|c|c|c|c|c|c|c|c|c|c|}
\hline & \multirow{2}{*}{\multicolumn{2}{|c|}{$\begin{array}{l}\text { Total effect of } \\
\text { incomet }\end{array}$}} & \multicolumn{4}{|c|}{ Models with absolute food choice motives } & \multicolumn{4}{|c|}{ Models with relative food choice motives } \\
\hline & & & \multicolumn{2}{|c|}{$\begin{array}{l}\text { Direct effect of } \\
\text { income }\end{array}$} & \multicolumn{2}{|c|}{$\begin{array}{l}\text { Specific indirect } \\
\text { effects }\end{array}$} & \multicolumn{2}{|c|}{$\begin{array}{l}\text { Direct effect of } \\
\text { income }\end{array}$} & \multicolumn{2}{|c|}{$\begin{array}{l}\text { Specific indirect } \\
\text { effects }\end{array}$} \\
\hline & $\beta$ & SE & $\beta$ & SE & $\beta$ & SE & $\beta$ & SE & $\beta$ & SE \\
\hline \multicolumn{11}{|c|}{ Vegetables/fruitł ( $n$ 3565) } \\
\hline Health & $0 \cdot 12^{\star \star \star}$ & 0.02 & $0 \cdot 11^{\star \star \star}$ & 0.02 & 0.005 & 0.004 & $0 \cdot 10^{\star \star \star}$ & 0.02 & $0 \cdot 020^{\star \star \star}$ & 0.004 \\
\hline Pleasure & $0 \cdot 12^{* \star *}$ & 0.02 & $0 \cdot 12^{\star \star \star}$ & 0.02 & 0.000 & 0.001 & $0 \cdot 12^{\star \star \star}$ & 0.02 & -0.003 & 0.002 \\
\hline Ethicality & $0 \cdot 12^{\star \star \star}$ & 0.02 & $0 \cdot 13^{\star \star \star}$ & 0.02 & $-0 \cdot 007^{\star *}$ & 0.002 & $0 \cdot 12^{\star \star *}$ & 0.02 & $-0.003^{*}$ & 0.002 \\
\hline Convenience & $0 \cdot 12^{\star \star \star}$ & 0.02 & $0 \cdot 12^{\star \star \star}$ & 0.02 & 0.000 & 0.001 & $0 \cdot 12^{\star \star \star}$ & 0.02 & -0.004 & 0.003 \\
\hline Price & $0 \cdot 12^{\star \star \star}$ & 0.02 & $0 \cdot 11^{\star \star \star}$ & 0.02 & $0 \cdot 010^{*}$ & 0.005 & $0 \cdot 09^{\star \star \star}$ & 0.02 & $0.033^{\star \star *}$ & 0.005 \\
\hline Familiarity & $0 \cdot 12^{* \star *}$ & 0.02 & $0 \cdot 12^{\star * \star}$ & $0 \cdot 02$ & $0.004^{*}$ & 0.002 & $0 \cdot 11^{\star * \star}$ & 0.02 & $0 \cdot 009^{* * *}$ & 0.002 \\
\hline \multicolumn{11}{|c|}{ Energy-dense foods $¥$ ( $n$ 3620) } \\
\hline Health & $-0.03^{*}$ & 0.02 & -0.03 & 0.02 & -0.004 & 0.004 & -0.01 & 0.02 & $-0.021^{\star \star \star}$ & 0.004 \\
\hline Pleasure & $-0 \cdot 03^{\star}$ & 0.02 & $-0.03^{*}$ & $0 \cdot 02$ & -0.001 & 0.001 & $-0.04^{*}$ & 0.02 & 0.004 & 0.003 \\
\hline Ethicality & $-0.04^{\star}$ & 0.02 & $-0.04^{\star}$ & 0.02 & $0.007^{\star *}$ & 0.002 & $-0.04^{\star}$ & 0.02 & $0 \cdot 004^{*}$ & 0.002 \\
\hline Convenience & $-0.03^{\star}$ & 0.02 & $-0.03^{\star}$ & 0.02 & 0.000 & 0.002 & $-0.04^{\star}$ & 0.02 & 0.004 & 0.003 \\
\hline Price & $-0 \cdot 03^{\star}$ & 0.02 & -0.03 & 0.02 & -0.007 & 0.005 & -0.01 & 0.02 & $-0.023^{\star \star \star}$ & 0.005 \\
\hline Familiarity & $-0.03^{*}$ & 0.02 & -0.03 & 0.02 & $-0.005^{\star}$ & 0.002 & -0.03 & 0.02 & $-0.008^{\star * *}$ & 0.002 \\
\hline
\end{tabular}

Significance of coefficient: ${ }^{\star} P<0.05,{ }^{* \star} P<0.01,{ }^{* \star *} P<0.001$.

tTotal effect $=$ direct effect + indirect effect.

$\neq$ The food consumption variables were square-root transformed in order to improve the normality of the distributions.

detailed information on sociodemographic factors, dietary habits and food choice motives in order to enhance understanding of SES inequalities in dietary intake. Applying structural equation modelling allowed us to explicitly test the direct and indirect effects among the variables of interest, and we took a novel analytical approach in terms of food choice motives. There are also limitations that should be taken into account in interpreting the results, however. The analyses were based on cross-sectional data, which does not allow for the ascertainment of causality or its direction. Nevertheless, SES is more likely to have an influence on food intake and food choice motives than vice versa. In addition, motivational factors are often considered to be determinants of behaviour rather than consequences. Assessing food consumption on a self-report FFQ allowed us to estimate longer-term intake, but all self-report dietary assessment methods are vulnerable to under- and over-reporting ${ }^{(47)}$. In order to take account of this, we adjusted the analyses for total energy intake and for several variables known to be related to reporting bias ${ }^{(30,48)}$. We measured two food choice motives, price and familiarity, on only one item ('is cheap' and 'is what I usually eat', respectively). This may not capture their nature comprehensively, but the associations were still consistent with those reported in previous studies assessing price and familiarity on more items $^{(8,11)}$. The present sample was initially representative of the Finnish population, but the attrition rate was relatively high due to the demanding study protocol. Non-participant analyses conducted in the context of previous FINRISK studies have shown that non-participants are more likely to have a low SES ${ }^{(49)}$ and this could have made our estimates more conservative.

\section{Conclusions}

The present results suggest that the less healthy dietary habits among individuals with a low SES are partly attributable to the higher priority they place on price and familiarity and the lower priority they give to health motives. Although differences between SES groups in the importance of food price and healthfulness have frequently been observed, the current findings imply that familiarity is another relevant motive that deserves further research. Furthermore, it is useful to analyse individuals' motive priorities rather than their absolute ratings of single motives, given that they may better reflect the complexity of the motive structure. On the practical level, reducing the price of healthy food could be an effective strategy for improving the diets of low-SES groups. A recent study conducted in real-life settings provided evidence that giving price discounts on healthier foods increased their purchasing irrespective of education or income level ${ }^{(50)}$. However, as Ni Mhurchu ${ }^{(51)}$ notes, more research is needed in order to evaluate the exact effects of a range of pricing strategies on food consumption, health and inequalities.

\section{Acknowledgements}

This study was supported by the Academy of Finland (grant numbers 118139, 136895 and 141005) and the Finnish Doctoral Program for Social Sciences (SOVAKO). The authors have no conflicts of interest to declare. H.K., S.M. and A.H. were involved in data collection. H.K. conceptualized the research questions, conducted 
statistical analyses and drafted the manuscript. S.S.-L., K.S., S.M. and A.H. helped to draft the manuscript and advised on issues related to socio-economic factors, food choice motives and dietary intake. All authors were involved in the planning of the study and read and approved the final manuscript.

\section{References}

1. Giskes K, Avendano M, Brug J et al. (2010) A systematic review of studies on socioeconomic inequalities in dietary intakes associated with weight gain and overweight/ obesity conducted among European adults. Obes Rev 11, 413-429.

2. Darmon N \& Drewnowski A (2008) Does social class predict diet quality? Am J Clin Nutr 87, 1107-1117.

3. James WP, Nelson M, Ralph A et al. (1997) Socioeconomic determinants of health. The contribution of nutrition to inequalities in health. BMJ 314, 1545-1549.

4. Galobardes B, Morabia A \& Bernstein MS (2001) Diet and socioeconomic position: does the use of different indicators matter? Int J Epidemiol 30, 334-340.

5. Miura K, Giskes K \& Turrell G (2012) Socio-economic differences in takeaway food consumption among adults. Public Health Nutr 15, 218-226.

6. Thornton LE, Bentley RJ \& Kavanagh AM (2011) Individual and area-level socioeconomic associations with fast food purchasing. J Epidemiol Community Health 65, 873-880.

7. Pereira MA, Kartashov AI, Ebbeling CB et al. (2005) Fastfood habits, weight gain, and insulin resistance (the CARDIA study): 15-year prospective analysis. Lancet 365, 36-42.

8. Steptoe A \& Wardle J (1999) Motivational factors as mediators of socioeconomic variations in dietary intake patterns. Psychol Health 14, 391-402.

9. Hupkens CLH, Knibbe RA \& Drop MJ (2000) Social class differences in food consumption. The explanatory value of permissiveness and health and cost considerations. Eur J Public Health 10, 108-113.

10. Ball K, Crawford D \& Mishra G (2006) Socio-economic inequalities in women's fruit and vegetable intakes: a multilevel study of individual, social and environmental mediators. Public Health Nutr 9, 623-630.

11. Steptoe A, Pollard TM \& Wardle J (1995) Development of a measure of the motives underlying the selection of food: the food choice questionnaire. Appetite 25, 267-284.

12. Glanz K, Basil M, Maibach E et al. (1998) Why Americans eat what they do: taste, nutrition, cost, convenience, and weight control concerns as influences on food consumption. J Am Diet Assoc 98, 1118-1126.

13. Connors M, Bisogni CA, Sobal J et al. (2001) Managing values in personal food systems. Appetite 36, 189-200.

14. Lennernas M, Fjellstrom C, Becker W et al. (1997) Influences on food choice perceived to be important by nationally-representative samples of adults in the European Union. Eur J Clin Nutr 51, Suppl. 2, S8-S15.

15. Bowman SA (2006) A comparison of the socioeconomic characteristics, dietary practices, and health status of women food shoppers with different food price attitudes. Nutr Res 26, 318-324.

16. Drewnowski A (2010) The cost of US foods as related to their nutritive value. Am J Clin Nutr 92, 1181-1188.

17. Sobal J, Bisogni CA, Devine CM et al. (2006) A conceptual model of the food choice process over the life course. In The Psychology of Food Choice, pp. 1-18 [R Shepherd and M Raats, editors]. Wallingford: CABI.

18. Sobal J \& Bisogni CA (2009) Constructing food choice decisions. Ann Behav Med 38, Suppl. 1, S37-S46.
19. Lappalainen R, Saba A, Holm L et al. (1997) Difficulties in trying to eat healthier: descriptive analysis of perceived barriers for healthy eating. Eur J Clin Nutr 51, Suppl. 2, S36-S40.

20. Beydoun MA \& Wang Y (2008) How do socio-economic status, perceived economic barriers and nutritional benefits affect quality of dietary intake among US adults? Eur J Clin Nutr 62, 303-313.

21. Schwartz SH (1992) Universals in the content and structure of values: theoretical advances and empirical tests in 20 countries. In Advances in Experimental Social Psychology, pp. 1-65 [M Zanna, editor]. New York: Academic Press.

22. Vartiainen E, Laatikainen T, Peltonen M et al. (2010) Thirtyfive-year trends in cardiovascular risk factors in Finland. Int J Epidemiol 39, 504-518.

23. Eertmans A, Victoir A, Notelaers G et al. (2006) The Food Choice Questionnaire: factorial invariant over western urban populations? Food Qual Prefer 17, 344-352.

24. Fotopoulos C, Krystallis A, Vassallo M et al. (2009) Food Choice Questionnaire (FCQ) revisited. Suggestions for the development of an enhanced general food motivation model. Appetite 52, 199-208.

25. Hu L-T \& Bentler PM (1999) Cutoff criteria for fit indexes in covariance structure analysis: conventional criteria versus new alternatives. Struct Equ Modeling 6, 1-55.

26. Cattell RB (1966) The scree test for the number of factors. Multivariate Behav Res 1, 245-276.

27. Verkasalo M, Tuomivaara P \& Lindeman M (1996) 15-year-old pupils' and their teachers' values, and their beliefs about the values of an ideal pupil. Educ Psychol 16, 35-47.

28. Schwartz SH \& Rubel T (2005) Sex differences in value priorities: cross-cultural and multimethod studies. J Pers Soc Psychol 89, 1010-1028.

29. Männistö S, Virtanen M, Mikkonen T et al. (1996) Reproducibility and validity of a food frequency questionnaire in a case-control study on breast cancer. J Clin Epidemiol 49, 401-409.

30. Paalanen L, Männistö S, Virtanen MJ et al. (2006) Validity of a food frequency questionnaire varied by age and body mass index. J Clin Epidemiol 59, 994-1001.

31. Reinivuo H, Hirvonen T, Ovaskainen ML et al. (2010) Dietary survey methodology of FINDIET 2007 with a risk assessment perspective. Public Health Nutr 13, 915-919.

32. Organisation for Economic Co-operation and Development (1982) The OECD List of Social Indicators. Paris: OECD Social Indicator Development Programme.

33. Craig CL, Marshall AL, Sjostrom M et al. (2003) International physical activity questionnaire: 12-country reliability and validity. Med Sci Sports Exerc 35, 1381-1395.

34. Muthen LK \& Muthen BO (1998-2009) Mplus User's Guide, 5th ed. Los Angeles, CA: Muthen \& Muthen.

35. Westenhoefer J (2005) Age and gender dependent profile of food choice. Forum Nutr 57, 44-51.

36. Cheung GW \& Rensvold RB (2002) Evaluating goodnessof-fit indexes for testing measurement invariance. Struct Equ Modeling 9, 233-255.

37. Giskes K, Turrell G, Patterson C et al. (2002) Socioeconomic differences in fruit and vegetable consumption among Australian adolescents and adults. Public Health Nutr 5, 663-669.

38. Dibsdall LA, Lambert N, Bobbin RF et al. (2003) Lowincome consumers' attitudes and behaviour towards access, availability and motivation to eat fruit and vegetables. Public Health Nutr 6, 159-168.

39. Inglis $\mathrm{V}, \mathrm{Ball} \mathrm{K} \&$ Crawford $\mathrm{D}$ (2005) Why do women of low socioeconomic status have poorer dietary behaviours than women of higher socioeconomic status? A qualitative exploration. Appetite 45, 334-343. 
40. Waterlander WE, de Mul A, Schuit AJ et al. (2010) Perceptions on the use of pricing strategies to stimulate healthy eating among residents of deprived neighbourhoods: a focus group study. Int J Behav Nutr Phys Act 7, 44.

41. Barker M, Lawrence WT, Skinner TC et al. (2008) Constraints on food choices of women in the UK with lower educational attainment. Public Health Nutr 11, 1229-1237.

42. Beaulac J, Kristjansson E \& Cummins S (2009) A systematic review of food deserts, 1966-2007. Prev Chronic Dis 6, A105.

43. Macintyre S (2007) Deprivation amplification revisited; or, is it always true that poorer places have poorer access to resources for healthy diets and physical activity? Int J Behav Nutr Phys Act 4, 32.

44. Pollard TM, Steptoe A \& Wardle J (1998) Motives underlying healthy eating: using the Food Choice Questionnaire to explain variation in dietary intake. J Biosoc Sci 30, 165-179.

45. Grunert KG, Baadsggaard A, Larsen HH et al. (1996) Market Orientation in Food and Agriculture. Norwell, MA: Kluwer Academic Publishers.
46. Scheibehenne B, Miesler L \& Todd PM (2007) Fast and frugal food choices: uncovering individual decision heuristics. Appetite 49, 578-589.

47. Maurer J, Taren DL, Teixeira PJ et al. (2006) The psychosocial and behavioral characteristics related to energy misreporting. Nutr Rev 64, 53-66.

48. Hirvonen T, Männistö S, Roos E et al. (1997) Increasing prevalence of underreporting does not necessarily distort dietary surveys. Eur J Clin Nutr 51, 297-301.

49. Harald K, Salomaa V, Jousilahti P et al. (2007) Nonparticipation and mortality in different socioeconomic groups: the FINRISK population surveys in 1972-92. J Epidemiol Community Health 61, 449-454.

50. Blakely T, Ni Mhurchu C, Jiang Y et al. (2011) Do effects of price discounts and nutrition education on food purchases vary by ethnicity, income and education? Results from a randomised, controlled trial. J Epidemiol Community Health 65, 902-908.

51. Ni Mhurchu C (2010) Food costs and healthful diets: the need for solution-oriented research and policies. Am J Clin Nutr 92, 1007-1008.

\section{Appendix}

\section{The four-factor structure of the shortened Food Choice Questionnaire}

\begin{tabular}{|c|c|c|c|c|}
\hline & Health & Convenience & Pleasure & Ethicality \\
\hline 1. Is low in fatt & $0 \cdot 81$ & & $-0 \cdot 10$ & \\
\hline 2. Helps me control my weightt & 0.78 & & & \\
\hline 3. Is low in caloriest & $0 \cdot 76$ & & & \\
\hline 4. Is high in fibre and roughage $\ddagger$ & $0 \cdot 66$ & & & $0 \cdot 16$ \\
\hline 5. Keeps me healthy & 0.49 & & $0 \cdot 12$ & $0 \cdot 15$ \\
\hline 6. Contains a lot of vitamins and mineralsł & 0.46 & & $0 \cdot 11$ & 0.31 \\
\hline 7. Keeps me awake/alert§ & 0.43 & & $0 \cdot 31$ & \\
\hline 8. Is good for my skin/teeth/hair/nails etc. $\neq$ & 0.43 & & $0 \cdot 19$ & 0.23 \\
\hline 9. Is high in protein $\ddagger$ & $0 \cdot 30$ & & $0 \cdot 15$ & $0 \cdot 21$ \\
\hline 10. Takes no time to prepare $\|$ & & 0.92 & & $-0 \cdot 14$ \\
\hline 11. Is easy to prepare\| & & $0 \cdot 80$ & $-0 \cdot 11$ & $-0 \cdot 16$ \\
\hline 12. Can be bought in shops close to where I live or work\| & & $0 \cdot 38$ & & $0 \cdot 14$ \\
\hline 13. Is cheap & & $0 \cdot 30$ & & \\
\hline 14. Is what I usually eatt† & & $0 \cdot 20$ & & $0 \cdot 20$ \\
\hline 15. Smells nicełł & & & 0.86 & \\
\hline 16. Makes me feel good§ & & & $0 \cdot 74$ & \\
\hline 17. Looks nicełł & & & $0 \cdot 61$ & \\
\hline 18. Tastes goodł⿰ & & & 0.57 & $-0 \cdot 12$ \\
\hline 19. Helps me cope with stress $\S$ & & & 0.52 & \\
\hline 20. Is organically grown & & & & 0.74 \\
\hline 21. Is packaged in an environmentally friendly way $\$$ & & & & 0.74 \\
\hline 22. Carries the Fairtrade mark & & & & 0.69 \\
\hline 23. Comes from countries I approve of politically $\$$ & & & & 0.68 \\
\hline 24. Contains no artificial ingredients \|\| & $0 \cdot 16$ & $-0 \cdot 10$ & & 0.65 \\
\hline 25. Contains no additives \|\| & 0.25 & & & 0.52 \\
\hline 26. Is domestically produced & $0 \cdot 10$ & & & 0.50 \\
\hline Cronbach's $\alpha$ & $0 \cdot 87$ & 0.67 & 0.79 & $0 \cdot 86$ \\
\hline
\end{tabular}

Total variance explained $45 \cdot 1 \%$. Factor loadings $\geq|10 \cdot 10|$ are shown and items with factor loadings $>|0 \cdot 35|$ are considered to belong to the respective factor. tlem is part of the weight control factor of the original Food Choice Questionnaire ${ }^{(11)}$.

fltem is part of the health factor.

Iltem is part of the mood factor.

IItem is part of the convenience factor.

- Item is part of the price factor.

ttltem is part of the familiarity factor.

¥tlem is part of the sensory appeal factor.

\$\&ltem is part of the ethical concern factor.

IIIItem is part of the natural content factor. 